\title{
Nuevo recuento cromosómico para Blechnum hastatum (Blechnaceae-Pteridophyta), con un estudio de la ontogenia y tipos de leptoporangios adultos
}

\author{
New chromosome count for Blechnum hastatum (Blechnaceae-Pteridophyta), with a \\ study of the ontogeny and types of adult leptosporangia
}

\author{
Graciela E. González ${ }^{1}$, Carmen Prada² \& Cristina H. Rolleri ${ }^{3}$ \\ 1Departamento de Ecología, Genética y Evolución (LACYE), Facultad de Ciencias Exactas y Naturales, Universidad de Buenos Aires, \\ Argentina. \\ ${ }^{2}$ Departamento de Biología Vegetal I, Facultad de Ciencias Biológicas, Universidad Complutense, Ciudad Universitaria, \\ 28040 Madrid, España. \\ ${ }^{3}$ Laboratorio de Estudios de Anatomía Vegetal Evolutiva y Sistemática (LEAVES), Facultad de Ciencias Naturales y Museo \\ de La Plata, 64 entre 120 y diagonal 113, B1904 DZB, La Plata, Argentina. \\ gonzalez@museo.fcnym.unlp.edu.ar; cpm@bio.ucm.es; crolleri@museo.fcnym.unlp.edu.ar
}

\section{RESUMEN}

\begin{abstract}
Se da a conocer un nuevo recuento cromosómico para Blechnum hastatum y se presenta un análisis de la ontogenia del leptosporangio en ese taxón y en $B$. occidentale, así como una comparación con leptosporangios adultos de otras especies y subespecies del género, como $B$. australe subsp. auriculatum, B. glandulosum y B. mochaenum subsp. mochaenum. En relación con la citología de $B$. hastatum, se contaron 33 bivalentes en diacinesis, lo que indica que se trata de un diploide con un número cromosómico $2 \mathrm{n}=66$, un dato que confirma un recuento previo y ubica al taxón en la secuencia de números cromosómicos básicos conocida para el género, es decir $\mathrm{x}=33$, que es el más frecuente. En el estudio de la ontogenia de los esporangios se comprobó que se forman a partir de iniciales que se encuentran sobre la comisura y sobre la base del indusio; que desarrollan un pedicelo formado por células cortas en tres hileras en B. hastatum, la condición aparentemente más común registrada para el género, y células largas, también en tres hileras, en $B$. occidentale. Los pedicelos alcanzan su máximo desarrollo antes de que la cápsula llegue a la etapa adulta. Los estomios tienen 6-8 células, las de la abertura engrosadas en forma de labio. Los anillos son verticales de hasta 14 células engrosadas en B. australe subsp. auriculatum y B. glandulosum, hasta 18 en B. hastatum y hasta 21 en B. mochaenum subsp. mochaenum y B. occidentale, llegan hasta la base misma de las cápsulas y el número de células engrosadas aparece como un carácter diagnóstico nuevo en el género.
\end{abstract}

Palabras clave: Blechnum, número cromosómico, desarrollo del leptosporangio, número de células del anillo, sistemática.

\begin{abstract}
Anew chromosome count on Blechnum hastatum, together with the study of the ontogeny and development of the leptosporangia of this taxon, and of B. occidentale is carried out here. Adult leptosporangia of other taxa of the genus Blechnum, such as those of $B$. australe subsp. auriculatum, B. glandulosum and B. mochaenum subsp. mochaenum are also compared. In relation with the cytology of $B$. hastatum, 33 bivalents at diakinesis were counted, indicating that it is a diploid with a chromosome number $2 n=66$, which coincides with a previous count, and also places the taxon in the sequence of basic chromosome numbers known for the genus, ie $x=33$, which seems to be the most frequent. The ontogeny of the leptosporangia was studied for the first time in B. hastatum and B. occidentale. The sporangia initiate from a single initial epidermal cell, which may belong to the commissural area or to the indusia; they develop a long pedicel with three rows of long or short cells, short cells being the most common condition found in B. hastatum, while long cells were seen in $B$. occidentale. The pedicels are at their maximum length before the capsule ripens. The stomium usually bears no more than $6-8$ cells in all species, with a labiate aperture. The capsules have an indurated vertical annulus, that reach the base of the capsule, and have up to 14 cells in $B$. australe subsp. auriculatum and B. glandulosum, up to 18 in B. hastatum and up to 21 in B. mochaenum subsp. mochaenum and $B$. occidentale; the number of indurate cells may be a new useful diagnostic trait in the genus.
\end{abstract}

KEYwoRDs: Blechnum, chromosome numbers, leptosporangium development, number of cells of the annulus, systematic. 


\section{INTRODUCCIÓN}

El género Blechnum L. (Blechnaceae) es cosmopolita, y se encuentra en América (en los Estados Unidos de América, Mesoamérica, Antillas y Sudamérica), Europa (hasta los Urales), África, Madagascar, Asia (hacia el E, hasta Japón), Melanesia, Australia, Nueva Zelanda y archipiélagos del Pacífico (Polinesia hasta Tahití, Rapa e Islas Marquesas) y es adventicio en Hawái. Reúne plantas terrestres, epifíticas o más raramente, anfibias, de áreas tropicales y sub-tropicales, selvas húmedas, bajas o montanas, bordes de selvas o bosques, sabanas o áreas perturbadas, humedales, vegas, turberas y pantanos fríos de las regiones e islas subantárticas, con un rango altitudinal que va desde el nivel del mar hasta los 4.500 $\mathrm{m}$ de altitud. Incluye unos 150 taxones, de los cuales 92 crecen en Mesoamérica y Sudamérica (Rolleri \& Prada 2006 b) y unos 21 en Argentina (Ponce 1996).

El número cromosómico es la característica cariotípica más comúnmente utilizada en los análisis citotaxonómicos ya que no está influido por las etapas de desarrollo de las plantas o por condiciones externas (Guerra 2008). A pesar de ser un parámetro cariotípico fácil de obtener, aporta información sustancial acerca del genoma de una especie y su conocimiento representa un paso importante en estudios de variación genética, taxonomía, filogenia y evolución, así como en estudios de niveles de ploidía, estructura y diversidad de los genomas (Walker 1966). El recuento de cromosomas en células mitóticas es relativamente sencillo de realizar y suministra datos confiables y altamente reproducibles; sin embargo en taxones con números cromosómicos muy altos resulta más apropiado efectuar recuentos meióticos debido a que los cromosomas se encuentran apareados formando bivalentes, a su disposición en diacinesis y al gran tamaño celular de los meiocitos (Guerra 2008).

Numerosos autores han documentado los números cromosómicos de pteridófitos, entre ellos Manton (1950), Tryon et al. (1975), Löve et al. (1977), Smith \& Mickel (1977), Dawson et al. (2000), Tindale \& Roy (2002), Windham \& Yatskievych (2003), Perrie et al. (2003), Buarque Marcon et al. (2003, 2005) y Bennert et al. (2005). En el caso de Blechnum se conocen los de unas 25 especies con números básicos (x) entre 29 y 36 , y con varios niveles de ploidía, desde diploides a hexaploides (Löve et al. 1977). Dawson et al. (2000) dieron a conocer un listado de números cromosómico de pteridófitos de Nueva Zelanda, y aportaron datos sobre numerosos taxones del paleotrópico, mientras que Walker (1966) efectuó recuentos en especies herbáceas, subarborescentes y arborescentes de Jamaica.

En relación con los taxones tratados en este estudio, de la Sota \& Cassá de Pazos (1983) registraron un número cromosómico de $\mathrm{n}=31$ para ejemplares de $B$. hastatum Kaulf. de San Martín de los Andes (Provincia de Neuquén,
Argentina) y un número $\mathrm{n}=62$ para $B$. australe subsp. auriculatum (Cav.) de la Sota. Más recientemente, JaraSeguel et al. (2006) presentaron recuentos de cuatro taxones de Blechnum de Chile: B. chilense (Kaulf.) Mett. (B. cordatum (Desv.) Hieron., Prada et al. 2008), B. hastatum, $B$. mochaenum Kunkel subsp. mochaenum (sub B. mochaenum Kunkel var. mochaenum), y B. penna-marina (Poir.) Kunth, para los que registraron un número cromosómico diploide de $2 n=66$, con número básico de $x=33$.

Las discrepancias mencionadas en los recuentos preexistentes llevaron a la realización de este nuevo estudio, al que se agregó el análisis de la ontogenia de los leptosporangios hasta su estado adulto, un aspecto con escasas referencias. Copeland (1947) mencionó la presencia de un anillo de dehiscencia formado por (14) 20 (28) células para la familia en general; de la Sota \& Gouvêa Labouriou (1961) analizaron la vena comisural en B. occidentale L., Kramer (1990) mencionó la formación de esporangios a partir de iniciales que se encuentran tanto sobre la comisura como sobre el indusio como un rasgo de Blechnaceae en general, y Smith et al. (2006) describieron leptosporangios con pies cortos a largos, formados por 3 hileras de células.

El estudio citológico de $B$. hastatum realizado aquí no sólo es un aporte al conocimiento de los números básicos existentes en el género sino que pretende resolver las discrepancias arriba mencionadas para ese taxón. La ontogenia del leptosporangio de B. hastatum y $B$. occidentale se efectuó en materiales procedentes de diversas localidades y las etapas adultas se compararon con las observadas en esporangios de B. australe subsp. auriculatum, B. glandulosum y B. mochaenum subsp. mochaenum (Rolleri \& Prada 2006 a), también de diversa procedencia, con el fin de introducir el análisis de un nuevo rasgo potencialmente útil en la sistemática del género.

\section{MATERIALES Y MÉTODOS}

El material para efectuar recuentos cromosómicos de $B$. hastatum fue recolectado por una de las autoras en los bosques andino-patagónicos hiperhúmedos de Argentina. Los ejemplares de referencia de esa subespecie y otros taxones analizados se citan en el Apéndice.

Las pinnas de frondas jóvenes se fijaron en una solución de 3:1 (alcohol etílico absoluto: ácido acético) a $4^{\circ} \mathrm{C}$ por 24 horas como mínimo, luego se pasaron a alcohol etílico al $70 \%$ y se almacenaron a $4^{\circ} \mathrm{C}$ hasta su estudio. Para realizar los recuentos cromosómicos de $B$. hastatum se estudiaron numerosos meiocitos en diacinesis-prometafase $\mathrm{I}$, y de entre todos se seleccionaron y analizaron las 10 mejores células.

La ontogenia del leptosporangio se ha documentado en materiales de $B$. hastatum de localidades de la Patagonia 
argentina y en material de $B$. occidentale de los bosques subtropicales del noroeste del país. Los resultados se han comparado con etapas intermedias y adultas observadas en esporangios de especímenes de otras localidades. Se han ilustrado, asimismo, esporangios adultos de $B$. australe subsp. auriculatum, B. glandulosum y B. mochaenum subsp. mochaenum, de numerosas localidades y diversa procedencia.

Para las preparaciones citológicas y para el estudio de la morfología esporangial se tomaron los leptosporangios de pinnas jóvenes y se realizaron aplastados del tejido esporógeno sobre portaobjetos conteniendo una gota de hematoxilina acética al 2\%. Luego de 30 minutos se observaron por medio de microscopio óptico de luz directa. Para el análisis de la meiosis durante la esporogénesis se realizaron las preparaciones necesarias para documentar todas las fases de la meiosis hasta la formación de las tétradas. Los recuentos cromosómicos se efectuaron en meiocitos en las etapas de diacinesis y prometafase I.

Las fotografías se tomaron mediante un microscopio Leica DMLB equipado con cámara digital. Para la individualización y recuento de los cromosomas se utilizó el programa gratuito MicroMeasure 3.3 (http://www. colostate.edu/Depts/Biology/MicroMeasure).

Los términos utilizados en citología son los clásicos para este tipo de trabajos; los utilizados en morfología externa e interna están en otros trabajos pteridológicos de las autoras (Prada et al. 2008; Rolleri et al. 2008), y en Lellinger (2002).

\section{RESULTADOS}

Estudios Citológicos EN $B$. HASTATUM

Los recuentos cromosómicos efectuados en $B$. hastatum revelaron un total de 33 bivalentes (Fig. 1B). Todos los meiocitos analizados (15 por etapa meiótica) mostraron meiosis regular, con apareamientos y segregaciones cromosómicas normales (Fig. 1B-E).

La etapa de profase I se ilustra en la Fig. 1 A. Los apareamientos cromosómicos que se observaron en diacinesis fueron un total de 33 bivalentes (Fig. 1B). La metafase I se observa en la Fig. 1C. En anafase I la migración fue regular y no se observaron puentes de inversión que pudieran indicar restructuraciones cromosómicas. La telofase I originó díadas balanceadas y sin micronúcleos en todas las células estudiadas (Fig. 1E). La meiosis II fue regular en todos los esporocitos estudiados y dio como resultado la formación de tétradas balanceadas (Fig. 1F).

ONTOGENIA Y MORFOLOGÍA DE LOS LEPTOSPORANGIOS Blechnum australe subsp. auriculatum y $B$. hastatum tienen frondas subdimórficas, B. glandulosum y B. occidentale, monomórficas y B. mochaenum subsp. mochaenum es un taxón dimórfico. Los leptosporangios se originan por una división oblicua o transversal de una célula epidérmica situada sobre la comisura o sobre el indusio mismo, más o menos cerca de su base.

En B. australe subsp. auriculatum la comisura es siempre continua y tiene posición medial a costal, en $B$. hastatum la comisura es discontinua y tiene una posición medial a submarginal, en ambas con escaso tejido estéril en la pinna fértil, mientras que en $B$. glandulosum y $B$. occidentale la comisura es continua y tiene posición casi costal con abundante tejido estéril en la pinna fértil. Blechnum mochaenum subsp. mochaenum presenta pinnas fértiles extremadamente contraídas y diferentes de las estériles.

En B. hastatum y B. occidentale las primeras etapas en el desarrollo son muy similares y los esporangios se originan a partir de una inicial de la epidermis o del indusio. La primera división suele ser periclinal (ocasionalmente algo oblicua) y produce 2 células, la basal dará origen al pedicelo y la apical a la cápsula (Figs. 2 A-C, 3 A). Las mitosis subsiguientes, en rápida sucesión, determinan la aparición de células parietales estériles, que delimitan la célula o células que originarán el tejido esporógeno (Figs. 2 D-H, 3 A-D). Las células parietales producen divisiones predominantemente anticlinales y ocasionalmente periclinales (Fig. 2 E-H), las mitosis sucesivas llevan a la proliferación del tejido esporógeno en la cápsula (Figs. 2 G-H) y empieza a delimitarse el futuro tapete (Fig. 4 A-B).

Así, los leptosporangios inmaduros presentan un pedicelo corto y poco diferenciado, mientras que la cápsula constituye una masa más o menos esférica con paredes uniformemente delgadas y núcleos de gran volumen que ocupan la mayor parte del lumen celular. La zona basal que formará posteriormente el pedicelo tiene 8-10 células isodiamétricas con las mismas características morfológicas. Se delimita una roseta o corona de células isodiamétricas entre el pedicelo y la cápsula (Figs. $2 \mathrm{~J}, \mathrm{~K}$ ), que puede persistir hasta la etapa adulta o confundirse con el resto del pedicelo.

A partir de esta etapa se observan ciertas diferencias entre ambos taxones:

a) Desarrollo en $B$. hastatum

El leptosporangio inmaduro tiene una cápsula globosa elipsoidal formada por células isodiamétricas, una pared sin engrosamientos, un tapete definido y un pedicelo 812 (18)-celular, con células en 2-3 hileras; se distingue una corona o roseta de hasta 8 células isodiamétricas, situadas en la base de la cápsula que presenta células con paredes delgadas y grandes núcleos centrales, el tapete y el tejido esporógeno que se visualiza como una masa central diferenciada (Figs. 2 I-K, 4 C). 
El pedicelo crece rápidamente, alcanza 18 células con una relación largo/ancho ( $1 /$ a) de $2: 1$ que se disponen en 3 hileras de 6 , persiste una roseta celular en la base de la cápsula, de 8-10 células isodiamétricas (Fig. 4D).

La pared de la cápsula tiene células cuyos núcleos grandes van adquiriendo posición parietal interna $\mathrm{y}$ engrosamientos anticlinales incipientes en las que integrarán el anillo, claramente vertical (Fig. 2K); existe un tapete secretor y el tejido esporógeno es una masa central con tétradas inmaduras (Fig. 4D). En el anillo se distinguen entre 15 y 18 células engrosadas y el estomio es una zona ininterrumpida de unas 8 células; cuando la cápsula madura, dos de estas células empiezan a separarse y presentan un borde labiado (Fig. $2 \mathrm{~K}$ ).

En el leptosporangio adulto, el pedicelo puede estar constituido por 21-24 (más raramente hasta 30 ) células, más o menos cortas, con una relación 1/a de 2-3:1, dispuestas en 3 hileras de 7-8 (más raramente hasta 10); la roseta superior no se alarga y está formada por hasta 12 células. La cápsula tiene un anillo vertical de 18 células engrosadas que llega hasta la roseta y un estomio de 6-8 células, dos de éstas labiadas (Fig. 2 Q). En esta etapa el tejido esporógeno se ha dividido meióticamente para producir tétradas y éstas empiezan a madurar para producir esporas.

\section{b) Desarrollo en B. occidentale}

El leptosporangio inmaduro tiene una cápsula globosa, esférica, más pequeña que la observada en esta etapa de $B$. hastatum, formada por células más pequeñas y numerosas, también isodiamétricas, y el pedicelo raramente está formado por más de 8 (Fig. 2 L). El pedicelo comienza a elongarse por alargamiento de las células que se disponen en 3 hileras. Entre el pedicelo y la cápsula se visualiza una roseta o corona celular poco definida de unas 8 células, que no está presente en todos los esporangios. La pared de la cápsula tiene células de paredes delgadas y grandes núcleos centrales, se define el tapete y el tejido esporógeno masivo (Fig. $2 \mathrm{M}-\mathrm{N}$ ).

El pedicelo crece rápidamente y su longitud se debe al alargamiento celular más que al aumento en el número de células que pueden llegar hasta 27, en 3 hileras de 9, cuya relación 1/a es 3-4:1 (Fig. 2 M-N). La presencia de una roseta de células cortas en la base de la cápsula es errática. En la cápsula propiamente dicha se observa una pared en vías de maduración, un estomio de 6-8 células, un tapete (Fig. $2 \mathrm{M}-\mathrm{N})$ y el tejido esporógeno que se visualiza como una masa central. El anillo en formación es vertical, tiene 17-19 células que llegan hasta la base de la cápsula y el estomio puede estar limitado a 6-7 células aunque puede haber más.

El pedicelo definitivo está formado por 27 (30) células, en 3 hileras de 9-10, con una relación 1/a de 6:1 o más y suele romperse con facilidad (Fig. $2 \mathrm{O}$ ). La cápsula madura tiene una pared bien formada, un anillo vertical de 18-21 células con evidentes engrosamientos en $U$ y un estomio de 8-9 células pequeñas, con dos células de abertura claramente labiadas, con espesamientos parietales uniformes que no se observan en otras células vecinas del estomio (Fig. 2 O-P). Hay tétradas o esporas ya diferenciadas.

c) Esporangios adultos en otras especies de Blechnum Los leptosporangios adultos de $B$. australe subsp. auriculatum tienen un pedicelo con base 1-seriada 3celular que se continúa en 2-3 hileras, con 4 (6) células por hilera; la relación 1/a es de 4:1en las hileras basales y de $3: 1$ en el resto. La cápsula tiene un anillo vertical, de 12-14 (16) células, que llega hasta la base y un estomio marcadamente labiado de 8 o más células (Fig. 2 R-S).

Los leptosporangios adultos de $B$. glandulosum tienen un pedicelo de 2 hileras en la base, luego 3 , y presentan 5 (6) células por hilera, con una relación $1 / a$ variable. La cápsula tiene un anillo vertical que llega hasta la base, de 12-14 (15) células y un estomio apenas labiado de 8-9 o más células (Fig. $2 \mathrm{~T}$ ).

Los leptosporangios adultos de B. mochaenum subsp. mochaenum tienen un pedicelo de 3 hileras, con 6-9 células por hilera, con una relación 1/a de 2-3:1 y una corona o roseta de 4-8 células \pm isodiamétricas; el anillo es vertical, llega hasta la base, tiene 18-21 células y el estomio presenta hasta 12 células pequeñas, isodiamétricas, con un par apenas labiado, poco prominente (Fig. 2U).

Estos resultados aparecen resumidos en las Tablas I y II. 

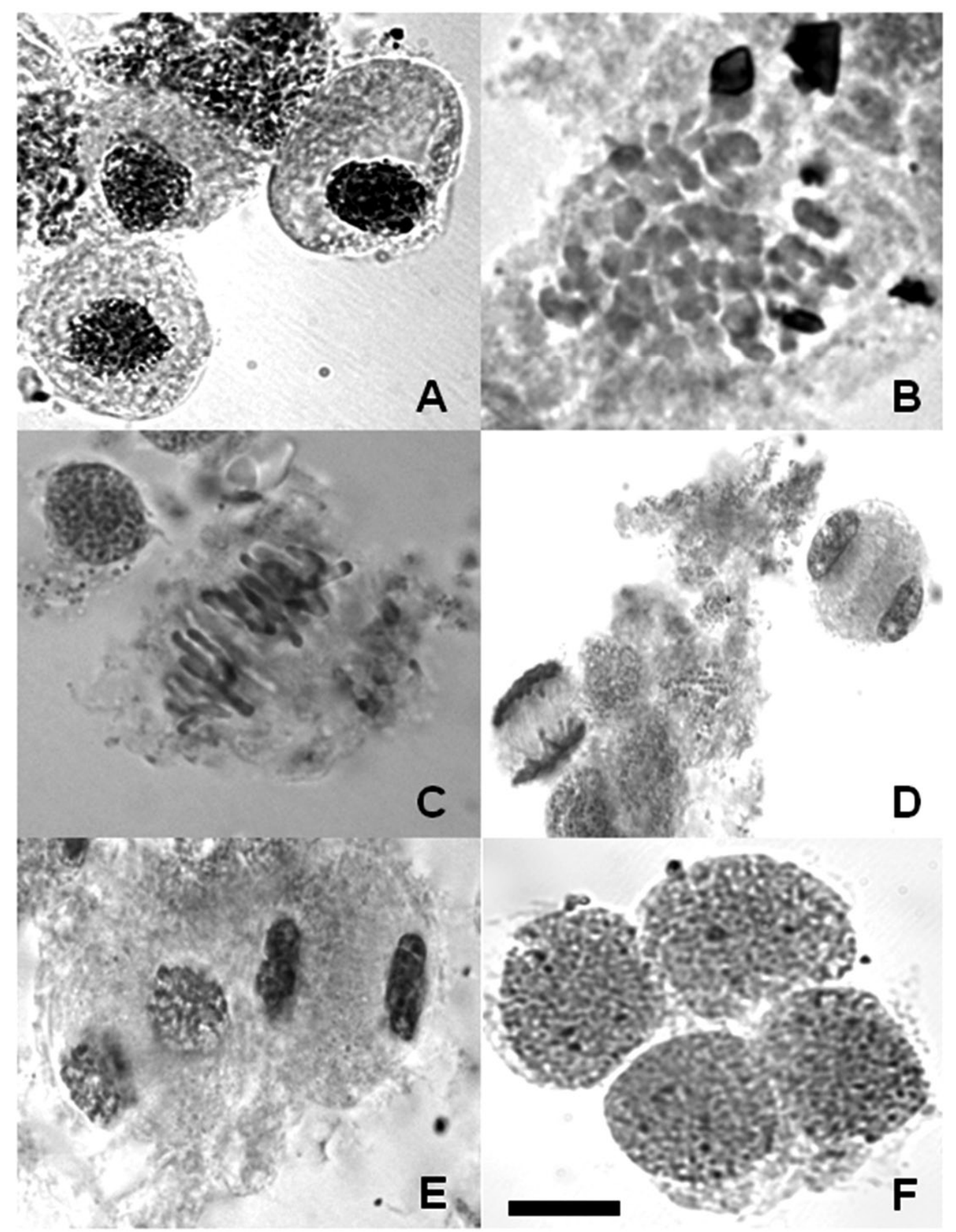

FIgURA 1. Etapas meióticas de Blechnum hastatum. A: Profases. B: Bivalentes en diacinesis. C: Metafase I. D-E: Telofases I. F: Tétradas. Barra $=15 \mu \mathrm{m}$ en A, D; $5 \mu \mathrm{m}$ en B, C, E, F.

FIgURe 1. Meiotic stages of Blechnum hastatum. A: Prophases. B: Bivalents in diakinesis. C: Metaphase I. D-E: Telophases I. F: Tetrads. Bar $=15 \mu \mathrm{m}$ in A, D; $5 \mu \mathrm{m}$ in B, C, E, F. 


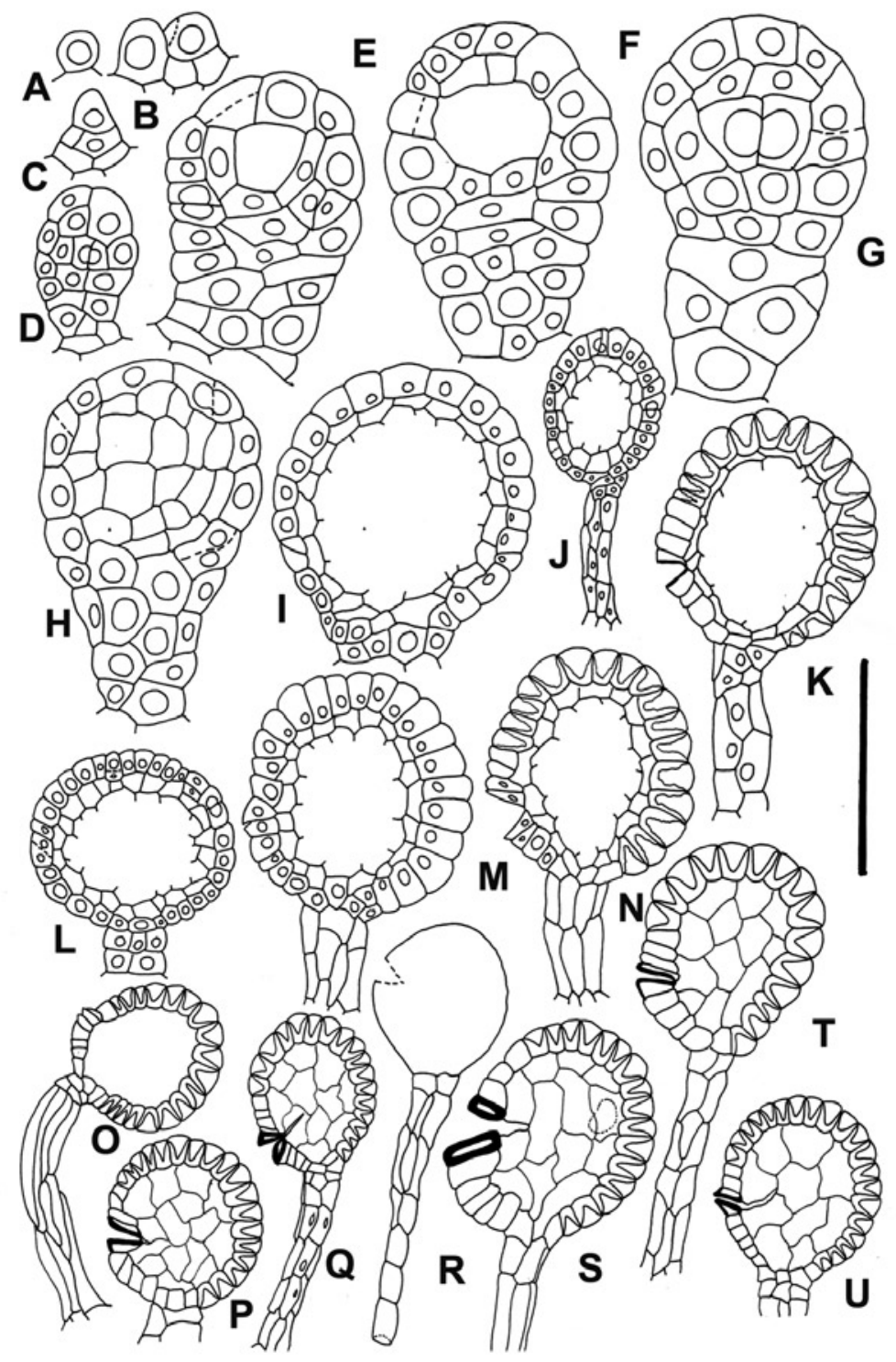

Figura 2. Etapas del desarrollo del esporangio y esporangios adultos en especies de Blechnum. A-H: Etapas de la ontogenia del leptosporangio comunes para B. hastatum y B. occidentale. A-B: Iniciales del leptosporangio. C: Primeras divisiones. D: Inicio de la delimitación del pedicelo y la cápsula. E-F: Formación de la pared, crecimiento del pedicelo, inicio del tapete y del tejido esporógeno. G-H: Aumento de las divisiones en el tejido esporógeno. I-K: B. hastatum, esporangios juveniles, con creciente definición de las paredes estériles, el tapete y aumento masivo del tejido esporógeno (no ilustrado). L-N: B. occidentale, esporangios juveniles, con creciente definición de las paredes estériles, el tapete y aumento masivo del tejido esporógeno (no ilustrado). O-P: B. occidentale, esporangio adulto. Q: B. hastatum, esporangio adulto. R-S: B. australe subsp. auriculatum, esporangio adulto. T: B. glandulosum, esporangio adulto. U: B. mochaenum subsp. mochaenum, cápsula del esporangio adulto. Barra $=30 \mu \mathrm{m}$ en A-H; $85 \mu \mathrm{m}$ en I; $200 \mu \mathrm{m}$ en J, O, Q, R; $100 \mu \mathrm{m}$ en $\mathrm{K}-\mathrm{N} ; 120 \mu \mathrm{m}$ en $\mathrm{S}, \mathrm{T} ; 180 \mu \mathrm{m}$ en $\mathrm{P}, \mathrm{U}$.

FIGURE 2. Stages of the sporangia development and adult sporangia in species of Blechnum. A-H: Stages of ontogeny of the sporangium in common to B. hastatum and B. occidentale. A-B: Leptosporangia initials. C: First divisions. D: Beginning of the delimitation of the pedicel and the capsule. E-F: Formation of the wall, pedicel growth, initiation of tapetum and sporogenous tissue. G-H: Proliferation of divisions in the sporogenous tissue. I-K: B. hastatum, young sporangia, with increasing definition of sterile walls, the tapetum, and massive growth of the sporogenous tissue (not shown). L-N: B. occidentale, young sporangia, with increasing definition of sterile walls, the tapetum, and massive growth of the sporogenous tissue (not shown). O-P: B. occidentale, adult sporangium. Q: B. hastatum, adult sporangium. R-S: B. australe subsp. auriculatum, adult sporangium. T: B. glandulosum, adult sporangium. U: B. mochaenum subsp. mochaenum, adult sporangium capsule. Bar $=30 \mu \mathrm{m}$ on A-H; $85 \mu \mathrm{m}$ in I; $200 \mu \mathrm{m}$ in J, O, Q, R; $100 \mu \mathrm{m}$ in $\mathrm{K}-\mathrm{N} ; 120 \mu \mathrm{m}$ in S, T; 180 $\mu \mathrm{m}$ in $\mathrm{P}, \mathrm{U}$. 
Gayana Bot. 67(1), 2010

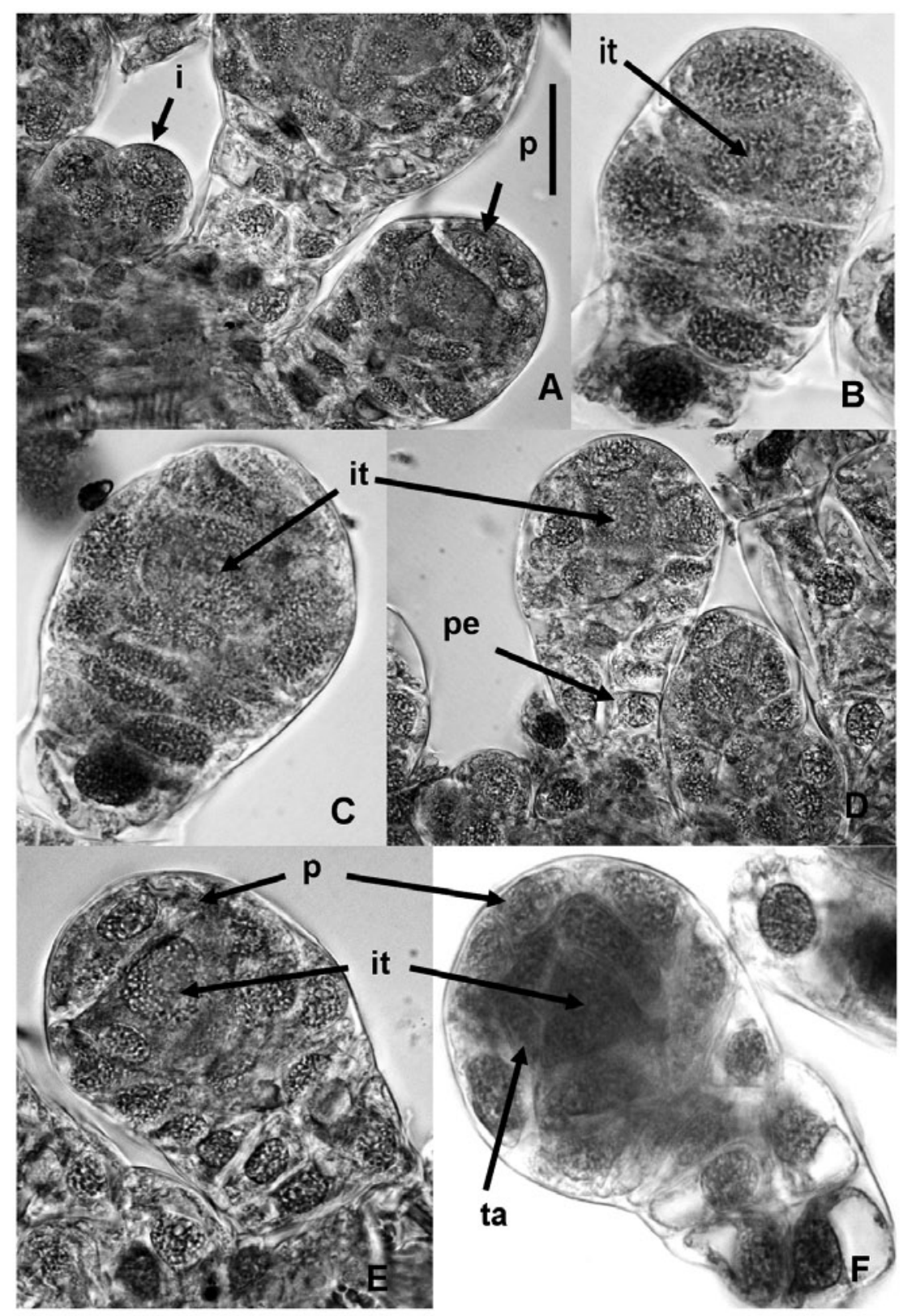

FIgURA 3. Desarrollo de esporangios en Blechnum hastatum. A: Iniciales esporangiales, esporangios con inicial del tejido esporógeno y pedicelo corto y esporangios con pedicelo y cápsula más desarrollados (centro). B-C: Detalles de esporangios con pared en desarrollo, inicial del tejido esporógeno y pedicelo corto. D: Detalle de un esporangio con pedicelo en etapa de alargamiento. E: Divisiones en el tejido esporógeno e inicio del tapete. F: Etapa subsiguiente respecto de la ilustrada en E. i, inicial del esporangio; it, iniciales del tejido esporógeno; p, pared de la cápsula; pe, pedicelo juvenil; ta, tapete juvenil. Barra=12 $\mu \mathrm{m}$ en A, D; $8 \mu \mathrm{m}$ en B, C, E-F.

FIGURE 3. Ontogeny of sporangia in Blechnum hastatum. A: Sporangia initials, sporangia with initial cells of the sporogenous tissue and a short pedicel, and sporangia with pedicel and capsule in more advanced developmental stages (centre). B-C: Detail of sporangia with developing wall, sporogenous tissue initial, and a short pedicel. D: Detail of a sporangium with pedicel in elongation stage. E: Divisions in the sporogenous tissue, and beginning of the formation of the tapetum. F: Stage subsequent to the one illustrated in E. i, sporangium initial; it, initial cells of the sporogenous tissue; $\mathrm{p}$, capsule wall; pe, juvenile pedicel; ta, juvenile tapetum. Bar= $12 \mu \mathrm{m}$ in $\mathrm{A}$, D; $8 \mu \mathrm{m}$ in $\mathrm{B}, \mathrm{C}, \mathrm{E}-\mathrm{F}$. 


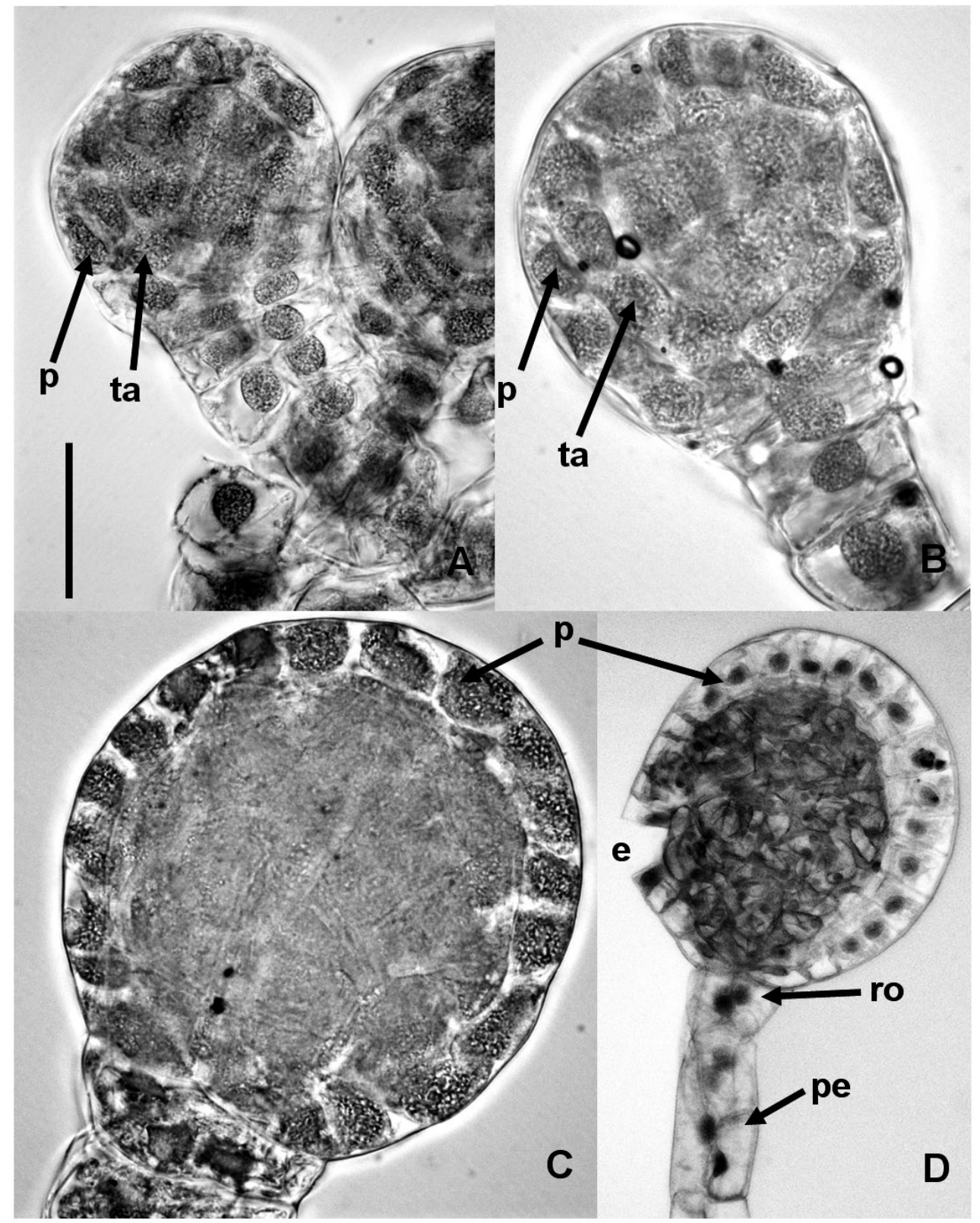

Figura 4. Desarrollo de esporangios en Blechnum hastatum. A-B: Etapas en el desarrollo de la cápsula y del pedicelo. C-D: Maduración de la pared de la cápsula, tapete y tejido esporógeno. C: Cápsula en vías de maduración y roseta basal evidente. D: Leptosporangio casi adulto con estomio definido, anillo vertical con pared en proceso de engrosamiento, roseta persistente y pedicelo. e, estomio; $p$, pared de la cápsula; pe, pedicelo; ro, roseta; ta, tapete. Barra $=20 \mu \mathrm{m}$ en A, C; $25 \mu \mathrm{m}$ en B; $50 \mu \mathrm{m}$ en D.

Figure 4. Development of sporangia in Blechnum hastatum. A-B: Developmental stages of the capsule and the pedicel. C-D: Maturation steps of the capsule wall, tapetum, and sporogenous tissue. C: Capsule in the process of maturation, with a clear basal rosette. D: An almost adult leptosporangia, with defined stomium, a vertical annulus with the walls in wall thickening process, persistent rosette, and pedicel. e, stomium; p, capsule wall; pe, pedicel; ro, rosette; ta, tapetum. Bar $=20 \mu \mathrm{m}$ in A, C; $25 \mu \mathrm{m}$ in B; $50 \mu \mathrm{m}$ in D. 
Gayana Bot. 67(1), 2010

TABLA I. Comparación de las etapas de desarrollo del leptosporangio en Blechnum hastatum y B. occidentale.

TABLE I. Comparison of stages of sporangium development in Blechnum hastatum and B. occidentale.

\begin{tabular}{lll}
\hline ETAPAS & B. hastatum & B. occidentale \\
\hline
\end{tabular}

1

El esporangio se origina de una inicial de la epidermis o del indusio. La primera división suele ser periclinal (ocasionalmente algo oblicua) y produce 2 células, la basal dará origen al pedicelo y la apical a la cápsula. En la cápsula las mitosis subsiguientes determinan las células parietales estériles y éstas delimitan la célula/células que originarán el tejido esporógeno.

2

Las células parietales producen ocasionales divisiones periclinales. Prolifera el tejido esporógeno en la cápsula y empieza a delimitarse el futuro tapete. Se alarga el pedicelo y en algunos casos se empieza a delimitar una roseta o corona de células isodiamétricas entre el pedicelo y la cápsula.

3

Esporangio pluricelular inmaduro

4

Alargamiento del pedicelo y comienzo de la maduración de la cápsula

5

Crecimiento del pedicelo y cápsula en desarrollo

6

Pedicelo adulto típico y cápsula en desarrollo

7

Cápsula pedicelo 8-12-celular, células isodiamétricas roseta no definida cápsula elipsoidal

pedicelo 16 -celular, 2 hileras, roseta 8 -celular cápsula con pared inmadura sin engrosamientos, tapete definido, tejido esporógeno masivo

pedicelo 18 -celular, células relación 1/a 2:1, 3 hileras de 6 células

roseta 8 celular persistente, células isodiamétricas

cápsula con pared madura y engrosamientos anticlinales, tapete glandular y tejido esporógeno definido, estomio 4-5-celular

pedicelo hasta 30 -celular, células relación 1/a 2-3:1, 3 hileras roseta de 4-8 células isodiamétricas cápsula como en la etapa anterior.

anillo vertical con engrosamientos en $\mathrm{U}$, tapete delimitado, tétradas presentes, estomio 4-5 celular colapsado y abierto pedicelo hasta 24-celular, células isodiamétricas

roseta no definida

cápsula esférica

pedicelo 27 -celular, 3 hileras

roseta indefinida o ausente cápsula con pared inmadura sin engrosamientos

tapete definido

tejido esporógeno masivo

pedicelo 27- celular, células relación 1/a 3-4:1, 3 hileras de 9 células roseta indefinida, a veces ausente cápsula con pared adulta, engrosamientos en $U$ marcados, tapete glandular, tejido esporógeno definido, estomio con 5-6 células.

pedicelo 30 - celular, a veces más, células grandes y largas, relación 1/a 6-7:1 cápsula como en la etapa anterior.

anillo vertical con engrosamientos en $U$, tapete bien delimitado, tétradas presentes, estomio 5-6 celular en vías de colapsar 
Citología y morfología esporangial en Blechnum: GonZÁLEz, G.E. ET AL.

TABLA II. Caracteres de los esporangios adultos en especies de Blechnum.

TABLE II. Characters of adult sporangia in Blechnum species.

\begin{tabular}{|c|c|c|c|c|c|c|}
\hline TAXONES & $\begin{array}{c}\mathrm{N}^{\mathrm{o}} \text { DE HILERAS DEL } \\
\text { PEDICELO }\end{array}$ & $\begin{array}{c}\mathrm{N}^{\circ} \text { DE } \\
\text { CÉLULAS DEL } \\
\text { PEDICELO }\end{array}$ & $\begin{array}{c}\text { REL. L/A } \\
\text { CÉLULAS } \\
\text { DEL } \\
\text { PEDICELO }\end{array}$ & $\begin{array}{l}\text { ROSETA DISTAL } \\
\text { DEL PEDICELO }\end{array}$ & $\begin{array}{c}\mathrm{N}^{\circ} \text { DE } \\
\text { CÉLULAS } \\
\text { DEL } \\
\text { ANILLO }\end{array}$ & $\begin{array}{l}\mathrm{N}^{0} \text { DE } \\
\text { CÉLULAS } \\
\text { DEL } \\
\text { ESTOMIO }\end{array}$ \\
\hline $\begin{array}{l}\text { B. australe subsp. } \\
\text { auriculatum }\end{array}$ & $\begin{array}{c}\text { base 1-seriada } \\
\text { 3-celular, luego } \\
2-3 \text { hileras, } 4(6) \\
\text { células por hilera }\end{array}$ & $3+(12-16)$ & $\begin{array}{c}4: 1 \text { las } \\
\text { basales, } \\
3: 1 \text { el } \\
\text { resto }\end{array}$ & $\begin{array}{l}\text { presente, } \\
3-6 \text { células } \\
\text { relación } 1 / \mathrm{a} \\
\text { variable }\end{array}$ & $12-14$ & $6-8$ \\
\hline B. hastatum & $\begin{array}{l}3 \text { hileras, 9-10 } \\
\text { células/hilera }\end{array}$ & $21-24(30)$ & $2-3: 1$ & $\begin{array}{c}\text { presente, } \\
\text { 4-8 células } \pm \\
\text { isodiamétricas }\end{array}$ & $18-19$ & $6-8$ \\
\hline B. glandulosum & $\begin{array}{l}2 \text { hileras en la } \\
\text { base, luego } 3,5(6) \\
\text { células/hilera }\end{array}$ & $12-14(15)$ & $3: 1$ & $\begin{array}{l}\text { presente, } \\
6 \text { células } \\
\text { relación } 1 / \mathrm{a} \\
\text { variable }\end{array}$ & $12-14$ & $6-9$ \\
\hline $\begin{array}{l}\text { B. mochaenum } \\
\text { subsp. mochaenum }\end{array}$ & $\begin{array}{l}3 \text { hileras, } 6(9) \\
\text { células por hilera }\end{array}$ & $18-21(27)$ & $2-3: 1$ & $\begin{array}{c}\text { presente } \\
\text { 4-8 células } \pm \\
\text { isodiamétricas }\end{array}$ & $18-21$ & $6-8$ \\
\hline B. occidentale & $\begin{array}{l}3 \text { hileras, } 4 \text { (5) } \\
\text { células/hilera }\end{array}$ & $\begin{array}{c}27-30 \text { (a } \\
\text { veces más) }\end{array}$ & $6-7: 1$ & $\begin{array}{c}\text { poco definida a } \\
\text { muy corta }\end{array}$ & $18-21$ & $6-8$ \\
\hline
\end{tabular}

\section{DISCUSIÓN Y CONCLUSIONES}

El análisis efectuado permitió conocer el número cromosómico de $B$. hastatum y deducir el nivel de ploidía: se contaron 33 bivalentes en diacinesis, lo que indica que se trata de un diploide con un número cromosómico $2 n=66$. Este dato coincide con recuentos previos registrados para varias especies de Blechnum y para B. hastatum, por Jara-Seguel et al. (2006) para ejemplares de Chile. Sin embargo, no coincide con las observaciones efectuadas por de la Sota \& Cassá de Pazos (1983). Los datos obtenidos se incluyen en la secuencia de números cromosómicos básicos propuesta por Walker (1966), es decir, $x=28,29$, $31,32,33,34$ y 36 , en la que $x=33$ parece ser el más frecuente.

El estudio de las etapas meióticas durante la esporogénesis permite detectar irregularidades que puedan conducir a la formación de esporas inviables. Aquí no se han observado anomalías en las células analizadas y los meiocitos mostraron apareamientos completos de cromosomas formando bivalentes, lo que indica que no se trata de un híbrido sino un taxón sexual normal. En relación con las esporas, se observó un desarrollo normal de las tétradas, que dieron origen a esporas de aspecto normal.

Acerca de $B$. australe subsp. auriculatum, considerada un tetraploide, el único recuento existente es el que registra un número cromosómico de $2 \mathrm{n}=124$ (de la Sota \& Cassá de Pazos 1983), es decir, un número básico de $\mathrm{x}=$ 31 , pero no hay otros recuentos del poliploide. Se trataría de un tetraploide de área geográfica amplia, posiblemente derivado tempranamente de un diploide de distribución más restringida. Los recuentos cromosómicos reportados para $B$. occidentale indican un número $2 n=124$, es decir, se trata de un tetraploide con un número básico de $\mathrm{x}=31$ (Walker 1985, Buarque Marcon et al. 2003).

En Pteridófitos en general, las primeras divisiones de las iniciales esporangiales conducen a la formación del pedicelo juvenil, la definición de la pared de la cápsula, las iniciales del arquesporio o tejido esporógeno y el tapete. El tejido esporógeno se desarrolla por mitosis y rápidamente aumenta el volumen de la cápsula. En relación con $B$. hastatum y $B$. occidentale, las etapas son esencialmente 
las indicadas, pero en este trabajo se han incluido los detalles del desarrollo, no previamente analizados, así como algunas diferencias existentes entre ambos taxones.

En el desarrollo de los leptosporangios de B. hastatum $\mathrm{y}$ de $B$. occidentale se han comprobado algunas diferencias destacables:

- Las células del pedicelo son cortas (relación 1/a 2-3:1) en $B$. hastatum y muy largas (relación 1/a 6-7:1) en $B$. occidentale; la relación 1/a 2-3:1 parece ser la más común en pedicelos de los restantes taxones.

- Las cápsulas inmaduras son elipsoidales en $B$. hastatum y esféricas en $B$. occidentale, en la misma etapa las células de la cápsula de esta última son más pequeñas y numerosas. - Las cápsulas adultas tienen un anillo vertical de 17-18 células en $B$. hastatum y 18-21 células en $B$. occidentale. En otros aspectos, el desarrollo de los leptosporangios de $B$. hastatum y de $B$. occidentale sigue pasos similares a los descritos para otros helechos leptosporangiados. En ambos taxones los esporangios se forman a partir de iniciales que se encuentran sobre la comisura y sobre la base del indusio; esto se observó igualmente en $B$. australe subsp. auriculatum y coincide con lo mencionado por Kramer (1990) para la familia; los pedicelos, crecen y alcanzan su máximo desarrollo, con 3 hileras de células, antes de que la cápsula llegue a la etapa adulta y los estomios presentan 68 (9) células en todo los taxones analizados, con un mayor engrosamiento de las células de abertura en $B$. australe subsp. auriculatum.

Los anillos verticales representan un rasgo del género y llegan hasta la base de la cápsula, pero se ha observado variación en el número de células engrosadas, que es de 12-15 (16) en B. australe subsp. auriculatum y B. glandulosum, 17-18 en B. hastatum y 18-21 en $B$. mochaenum subsp. mochaenum y $B$. occidentale. Este dato podría ser un nuevo rasgo diagnóstico en el género; Barker \& Hickey (2006) lo utilizaron exitosamente en especies de Adiantopsis Fée y en Blechnum representa un rasgo adicional, de fácil apreciación, dada la cantidad de esporangios que se forman en cada cenosoro.

\section{AGRADECIMIENTOS}

Este trabajo es parte de un proyecto acreditado por la Universidad Nacional de Las Plata (PI N 11/558) en el que participan las autoras, $\mathrm{y}$ ha sido financiado en parte por el Ministerio de Ciencia e Innovación de España, Proyecto CGL 2009-13622 (subprograma BOS). G. González y C. Rolleri son Investigadoras del Consejo Nacional de Investigaciones Científicas y Técnicas (CONICET). Las autoras agradecen especialmente a la Dra. Lidia Poggio por facilitar el Laboratorio de Citogenética y Evolución de la Facultad de Ciencias Exactas y Naturales de la Universidad de Buenos Aires.

\section{BIBLIOGRAFÍA}

BARKER, M.S. \& R.S. HiCKey. 2006. Taxonomic revision of Caribbean Adiantopsis (Pteridaceae). Annals of the Missouri Botanical Garden 93: 1-31.

Bennert, W., M. Lubienski, S. Körner \& M. Steinberg. 2005. Triploidy in Equisetum subgenus Hippochaete (Equisetaceae, Pteridophyta). Annals of Botany 95: 807815.

Buarque Marcon, A., I. Carneiro \& M. Guerra. 2003. Cariologia de algunas espécies de pteriodófitas ocorrentes no nordeste do Brasil. Acta Botânica Brasilica 17: 19-26.

Buarque Marcon, A., I. Carneiro \& M. Guerra. 2005. Variation in chromosome numbers, CMA bands and $45 \mathrm{~S}$ rDNA sites in species of Selaginella (Pteridophyta). Annals of Botany 95: 271-276.

Copeland, E.B. 1947. Genera Filicum. Waltham, Massachussetts. USA. 245 pp.

Dawson, M., P. Brownsey \& J. Lovis. 2000. Index of chromosome numbers of indigenous New Zealand pteridophytes. New Zealand Journal of Botany 38: 25-46.

Guerra, M. 2008. Chromosome numbers in plant cytotaxonomy: concepts and implications. Cytogenetic and Genome Research 120: 339-350.

Jara-Seguel, P., M. Romero-Mieres \& C. Palma-Rojas. 2006. Chromosome numbers of chilean Pteridophytes: first contribution. Gayana Botánica 63: 115-118.

Kramer, K.U. 1990. Blechnaceae. In: E. Kubitzki (ed.), The families and genera of vascular plants, I. Pteridophytes and Gymnosperms, 60-68. Springer Verlag.

Lellinger, D.B. 2002. A Modern Multilingual Glossary of taxonomic Pteridology. Pteridologia 3, 246 pp.

Löve, A., D. Löve \& R. Pichi-Sermolli. 1977. Cytotaxonomical Atlas of the Pteridophyta. J. Cramer, Vaduz. 398 pp.

Manton, I. 1950. Problems of cytology and evolution in the Pteridophyta. Cambridge University Press. London. 316 pp.

Perrie, L., P. Brownsey, P. Lockhart \& M. Largie. 2003. Evidence for an allopolyploid complex in New Zealand Polystichum. New Zealand Journal of Botany 41: 189215.

Ponce, M. 1996. Pteridophyta. Catálogo de las plantas vasculares de la República Argentina, I. En: F.O. Zuloaga \& O. Morrone (eds.). Monographs of Systematic Botany, Missouri Botanical Garden 60: 1-79.

Prada, C., C.H. Rolleri, \& L.M. Passarelli. 2008. Morfología y distribución geográfica en Blechnum cordatum (Blechnaceae-Pteridophyta). Acta Botanica Malacitana 33: 29-46.

Rolleri, C.H. \& C. Prada. 2006a. Revisión de los grupos de especies del género Blechnum (Blechnaceae, Pteridophyta): el grupo Blechnum penna-marina. Acta Botanica Malacitana 31: 7-50

Rolleri, C.R. \& C. Prada 2006b. Catálogo comentado de las especies de Blechnum (Blechnaceae-Pteridophyta) de Mesoamérica y Sudamérica. Anales del Jardín Botánico de Madrid 63(1): 67-106.

Rolleri, C.H., C. Prada \& L.M. Passarelli. 2008. Estudios morfológicos y taxonómicos en Blechnum (Blechnaceae - Pteridophyta): Blechnum tabulare y B. magellanicum. Anales del Jardín Botánico de Madrid 65 (2): 169-175. 
Smith, A. \& J. Mickel. 1977. Chromosome counts for Mexican ferns. Brittonia 29: 391-398.

Smith, A.R., K.M. Pryer, E. Schuettpelz, P. Korrall, H. SChNeIDER \& P. WOLF. 2006. A classification for extant ferns. Taxon 55: 705-731.

Sota, E.R. de la \& L. Cassá de Pazos. 1983. Contribución al conocimiento biosistemático de las especies austrosudamericanas del género Blechnum L. (BlechnaceaePteridophyta). Lilloa 36: 77-83.

Sota, E.R. DE LA \& L. GouvêA Labouriou. 1961. Correlaciones entre esporangios y nervadura comisural en Blechnum occidentale L. (Blechnaceae). Anais da Academia Brasileira de Ciências 33: 225-239.

Tindale, M. \& S. Roy. 2002. A cytotaxonomic survey of the Pteridophyta of Australia. Australian Systematic Botany 15: 839-937.

Tryon, A., P. Bautista \& S. Araujo. 1975. Chromosome studies of Brazilian ferns. Acta Amazonica 5: 35-43.

WALKER, T.G. 1966. A cytotaxonomic survey of the pteridophytes of Jamaica. Transactions of the Royal Society of Edinburgh 66: 169-237.

WALKER, T.G. 1985. Cytotaxonomic studies of the ferns of Trinidad. The cytologicand taxonomic implications. Bulletin of the British Museum of Natural History, Botany 13: 149-249.

Windham, M. \& G. YATSKIEVYCH. 2003. Chromosome studies of cheilanthoid ferns (Pteridaceae, Cheilanthoideae) from the western United States and Mexico. American Journal of Botany 90: 1788-1800.

\section{APÉNDICE I, EJEMPLARES DE REFERENCIA}

Blechnum australe subsp. auriculatum

ARGENTINA; Buenos Aires, Peña Blanca en las Pampas, Née s.n. (MA230534, 213366, 213369). Ex planicie bonariensis, Expedición Malaspina, Née s. n. (MA 230540). Balcarce, Sierra La Barrosa, Cabrera et al. 17086 (MA 213325). Saavedra, Sierra Curá Malal, Cordón Lehman, Estancia "La Gruta". Proyecto Ventania s/c. 993 a-b (LP) [material con recuento cromosómico, $n=62$ metafase mitótica en gametófitos (de la Sota y Cassá de Pazos, 1983]. Córdoba, Calamuchita, Sierra Grande, Altos Pampa, A. Hunziker 7136 (LP). Tanti, Río Dulce, entre Tanti y San José, 750 m, Rodrigo 2252 (LP). La Rioja, Colón Gordillo: Sierra de los Clavos, (frente a Chamical), Bisonini et al. 1110 (LP). Misiones, Guaraní, Arroyo Guaraní, Ruta 15, Schinini et al. 28733 (CTES). Tucumán, Santa Ana, Castillón 41661 (LIL).

\section{Blechnum hastatum}

ARGENTINA; Chubut, Cushamén: Hoyo de Epuyén, Roig et al. 14643 (LP). Neuquén, Isla Victoria, Corte 2 (LP). Isla Victoria, Corte 54 (LP). Isla Victoria, Corte 70 (LP). San Martín de los Andes, Gentili s. n. (LP) [material con recuento cromosómico, $\mathrm{n}=31$ metafase mitótica en gametófitos, de la Sota y Cassá de Pazos, 1983]. San Martín de los Andes, Bridarolli 2182 (LP). San Martín de los Andes, cascada de Quila-Quina, 50-650 m, 28-11-2005,
Prada \& Fuertes s.n. (LP, MA). Cascada de Chachín, senda a Chachín, desvío del camino a Hua Hum, 30-11-2005, Prada \& Fuertes s.n. (LP, MA) [material con recuento cromosómico $x=33$, efectuado aquí]. CHILE; Arauco, Isla Mocha, camino entre el Faro Oeste y la Hacienda, WeldtRodríguez 1056/351 (LP). Concepción, Talcahuano, Parque Hualpén, de la Sota 6030 (LP). Talcahuano, Rocoto, de la Sota 6022 (LP). Coquimbo, prope Coquimbo, Neé s.n. (MA 230058). Malleco, Parque Nacional Contulmo, de la Sota 6008 (LP). Contulmo, Behn 20030 (LP). Osorno, Parque Nacional Puyehue, Roig et al. 13661 (LP). Islas de Juan Fernández, Robinson Crusoe (ex Mas a Tierra): south side of Cerro Alto, above Porto Inglés, Meyer 9568 (LP). On walls and floor of Spanish caves, San Juan Bautista, Cumberland Bay, Meyer 9586 (LP). In crevices, along stream in Quebrada Angosta, between beach and the falls, Meyer 9423 (LP). Marinero Alejandro Selkirk (ex Más Afuera), near mouth of Quebrada Vacas with the sea, Meyer 9347 (LP). Más Afuera. Quebrada Tongo, on west side of island, Stuessey \& Ruiz 8462 (MA 700917). Ex regno chilensis, Née s.n. (MA 230564).

\section{Blechnum glandulosum}

BRASIL; Paraná, Porto Amazonas, Fazenda S. Roque Do Capão, sobre blocos de pedra, Kummorrow 1077 (LP). Rio Grande do Sul, Porto Alegre, Yoao Flush 13685 (SI). Torres, São Pedro, Burkart 25047 (SI). COSTA RICA; Puntarenas, San Vito, Estación Biológica Las Cruces, Gabriel y Galán s.n. (MA). MÉXICO; sin localidad precisa, Herbario de Sessé y Mociño (MA 599840, MA 599841).

\section{Blechnum mochaenum subsp. mochaenum}

ARGENTINA; Neuquén, margen oriental del Lago Queñi, 820 m, Gentili 814 (LP). Isla Victoria, Diem 1192 (LP). Cascada de Chachín, senda a Chachín, desvío del camino a Hua Hum, Prada s.n. (LP, MA). Camino a Paimún, Prada s.n. (LP, MA). Lago Nahuel Huapi, Brazo Blest, Puerto Blest, camino a la cascada de los Cántaros, Prada s.n. (LP, MA). Chubut, Futaleufú, Parque Nacional Los Alerces, Lago Cisnes, Roig et al. 13907 (LP). Río Negro, Laguna Frías, Conte 16 (LP). CHILE; Arauco, Isla de Mocha: camino entre el Faro Oeste y La Hacienda, Cordón Central, WeldtRodríguez 1111/406 (CONC 34368, LP). Concepción: Coronel Santa Juana, Curalí, Rodríguez Ríos 2 (CONC 33807, LP). Talcahuano, Caleta Tumbes, de la Sota 6015 (LP). Llanquihue, Lago Puelo, Parra 11282 (LP). Malleco, Parque Nacional Contulmo, de la Sota 6009 (LP). Osorno, Parque Nacional Puyehue, Roig 13662 (LP) y Roig et al. 13659 (LP). Aguas Calientes, Debandi 9 (LP).

\section{Blechnum occidentale}

ARGENTINA; Jujuy, Ledesma, Dinelli s. n. (LIL) \& Dinelli 5109 (LIL). Capital: camino al Cucho, La Cuesta, Cabrera 15860 (LP). Capital, entre el Cucho y El Tunalito, 1400 m, 
Vervoorst et al. 4443 (LP). Misiones, Iguazú, Cataratas del Iguazú, Hunziker 848 (LIL). Iguazú, Cataratas, Schwarz 7156 (LIL). Iguazú, Cataratas, Krapovickas 2434 (LIL). Corrientes, Alvear, La Cruz, Tres Cerros, Cerro Nazareno, Zuloaga et al. 5359 (SI). Salta, Tartagal, San Pedro, Capurro 376 (LIL). Tartagal, San Pedro, Capurro 447 (LIL). Orán, río Santa María, Las Juntas, Castellanos 9 (LIL). Tucumán, Horco Molle, Ciudad, Nalls s.n. (LIL 444143). Quebrada San Rafael, Castillón 41739 (LIL). Quebrada Río Lules, de la Sota 1109 (LIL). Carretera de Tafí del Valle, Entrada a la Reserva de la Quebrada de Los Sosa, en taludes muy húmedos cerca del puente sobre el arroyo, 700 m, Prada \& Gallardo s.n. (MA). Subida desde San Pablo a Villa Nougués, 1200 m, Prada \& Gallardo s.n. (MA).
Parque de San Javier, cerca de la Residencia Universitaria, 1350 m, Prada \& Gallardo s.n. (MA). BOLIVIA; Tarija, entre Emborozú y La Mamora; borde de camino, ladera húmeda, Zuloaga et al. 1071 (SI). Chulumani, Sud Yungas. Bridarolli 4482, 4423 (LP). BRASIL; Paraná, Saltos do Iguaçú, Krapovickas \& Cristóbal 13368 (LP). Mina Gerais, Serra de Espinaço, Irwin et al. 23768 (LP). COSTA RICA; Puntarenas, San Vito, Estación Biológica Las Cruces, Gabriel y Galán s.n. (MA). ECUADOR; Montaña de S. Antonio, expedición Malaspina (MA 230567). MÉXICO; sin localidad precisa, Herbario Sessé y Mociño (MA 230542 ). PERÚ; San Martín: Lamás, Alonso Alvarado, Quebrada de Lejía, al oeste de San Juan de Pacayzapa, Schunke 5965 (LP). 